\title{
Dead Poets' Society: Teaching, Publish-or-Perish, and Professors' Experiences of Authenticity
}

\author{
Phillip Vannini \\ Royal Roads University
}

\begin{abstract}
Within social psychology, the concept of authenticity of the self has traditionally suffered from lack of definitional clarity. In this article, after conceptualizing authenticity as the phenomenological emotional experience of feeling true to one's self, the author empirically examines the diversity of emotions associated with various degrees of authenticity and inauthenticity. Data for this study are from semi-structured in-depth interviews with forty-six faculty members employed at a public research university in the United States. Professors' experiences of and dispositions toward teaching, and their experiences of authenticity and inauthenticity, are examined against the background of structural and cultural forces and changes in American higher education. Data interpretation shows that teaching is mostly a source of authenticity for professors in the humanities, and less for those professors who identify themselves primarily as researchers.
\end{abstract}

In recent years, the system of higher education in the United States has been subject to an inordinate amount of pressures toward change. Primarily due to economic downturns and to the consequent need for cuts in public spending, state and federal administrations and the general public have pushed for public universities to become more efficient, productive, accountable, and flexible (Gould 2003; Rhoades 1998; Sykes 1988; White and Hauck 2000). Besieged by multiple challenges, public universities and academic work have undergone a significant structural and cultural metamorphosis (Altbach 1997; Altbach, Berdhal, and Gumport 1994; Boyer 1990; Levine 1997). For example, public budget cuts have pushed institutions to pressure their faculty to do more funded research in order to secure higher amounts of grant moneys (Gould 2003; Slaughter and Leslie 1997; Smith 2000; White and Hauck 2000). Despite the existence of a vital debate on the present and future of academic work, no empirical studies have investigated the emotional dynamics of professors' experiences of adjustment to changing role demands. Additionally, whereas publi-

Direct all correspondence to Phillip Vannini, School of Communication and Culture, Royal Roads University, 2005 Sooke Road, Victoria, BC V9B 5Y2, Canada; e-mail: vannini@lycos.com.

Symbolic Interaction, Vol. 29, Issue 2, pp. 235-257, ISSN 0195-6086, electronic ISSN 1533-8665.

(c) 2006 by the Society for the Study of Symbolic Interaction. All rights reserved. Please direct all requests for permission to photocopy or reproduce article content through the University of California Press's Rights and Permissions website, at http://www.ucpress.edu/journals/rights.htm. 
cations on the structural organization of academia abound, ethnographic studies of professors' work and lives are rare. One of the goals of this research study is to begin to fill that void.

As professors attempt to cope with institutional pressures and adapt to the changing values, conventions, and practices of the academic social world, they are sure to experience feelings of inauthenticity. Inauthenticity is the experience of feeling untrue to one's self-an emotional experience that is known to lessen an individual's work satisfaction and sense of well-being (Erickson 1991, 1995; Hochschild 1983), as well as decrease organizational solidarity and productivity (see Fine 1996). But despite their significance for the self and society, the concepts of inauthenticity and authenticity have long suffered from definitional lack of clarity. Furthermore, no qualitative research exists on what it means to feel authentic or inauthentic. In fact, despite the attention paid to authenticity by researchers such as Fine (1996) in his fascinating study of kitchen workers and by Hochschild (1983) in her classic study of flight attendants, authenticity as a phenomenological experience remains in these works to a large extent under-defined and under-explored. Therefore, in an attempt to contribute to the social psychological literature on authenticity (Erickson 1991, 1995; Gecas 1986, 1991, 1994; Hochschild 1983; Holstein and Gubrium 2000; Turner 1976; Turner and Gordon 1981; Turner and Schutte 1981) and to the existential-phenomenological symbolic interactionist literature on the self and emotions (Denzin 1984; Douglas 1977; Douglas and Johnson 1977; Kotarba and Fontana 1984; Kotarba and Johnson 2002; Manning 1973; Tiryakian 1962, 1968), I examine here the multiple emotional qualities of the experiences of authenticity and inauthenticity. Forty-six in-depth interviews with professors employed at an American public research university provide the data for this study. Although my analytical focus remains on authenticity and inauthenticity, throughout the article I also pay close attention to the changing conditions of academic work in an attempt to understand emotionality in situated social interaction, and with a focus on teaching.

\section{AUTHENTICITY AND INAUTHENTICITY AS EMOTIONAL EXPERIENCES}

In everyday life, we refer to something as authentic when we associate with it properties of genuineness, realness, and at times even originality. But academically, there exist at least two ways of conceptualizing authenticity. Philosophers, humanists, and cultural critics may use the concept of authenticity when referring to the metaphysical properties of subjects, cultures, or works of art (in relation to authenticity in philosophy, see Golomb 1998). Social psychologists, instead, are generally interested in the pragmatic perception of authenticity of the self, in other words, in an individual's experience of feeling true or congruent with one's self (Turner 1976; Turner and Gordon 1981; Turner and Schutte 1981).

There is, of course, a very important difference between the pragmatic, social psychological experience of feeling true to one's self and the metaphysical notion of 
being a true self. Feeling true to one's self has nothing to do with the existence of an absolute and universal "true" self. Rather than relying on metaphysics or ideology, the social psychological conceptualization of authenticity draws upon pragmatism and symbolic interactionism, and especially on its existential current (see Douglas 1977; Douglas and Johnson 1977; Kotarba and Fontana 1984; Kotarba and Johnson 2002; Manning 1973; Tiryakian 1962, 1968). Through such an approach to authenticity, "the human agent is seen as a volitional being who seeks to find meaning in his transactions with the reality in which he is intrinsically related by the nature of existence; he is a being who fundamentally seeks meaning and a sense of life" (Tiryakian 1968:76). In other words, if as symbolic interactionists we believe that "humans will act toward things on the basis of the meanings that the things have for them" (Blumer 1969:2), we should believe that the meanings that an individual has associated with his/her sense of self will significantly shape his or her action, and the meanings associated with action will shape the sense of self.

Being true to one's self is a complex feeling, not an essential condition. As an emotional experience, authenticity is a feeling about the self (Erickson 1991, 1995; Hochschild 1983), or a self-feeling. Self-feelings are forms of reflexive consciousness "lived, experienced, articulated and felt" (Denzin 1984:1; also see Douglas 1977; Kotarba and Fontana 1984; Kotarba and Johnson 2002). Self-feelings are "sequences of lived emotionality, often involving the feeling and experiencing of more than one specific, named emotion" (Denzin 1984:3). Through the complex whole of emotional experiences, individuals meaningfully locate themselves in the world of social interaction (Franks 2003). All self-feelings are temporal, situational, reflexive, relational, deeply personal, and expressive of the person's self. Emotions function as signals of our state in the social environment (Shibutani 1961), as internal feelings critical in the evaluation of phenomena external to the body (Lyman 1981), as a link connecting the embodied self and its world (Denzin 1984), and generally as processes closely interconnected with reflexive thought, communication, and culture (Douglas 1977; Ellis 1991; Farberman 1989). Emotions play a constitutive role in the formation of the person; without emotions the relation between the self and society would be empty and meaningless (Denzin 1984; see also Douglas 1977; Kotarba and Fontana 1984; Kotarba and Johnson 2002). In sum, emotions lie at the core of the person and through them the self defines meaning (Denzin 1984).

The basic precept of authenticity is that when individuals feel congruent with their values, goals, emotions, and meanings they experience a positive emotion (authenticity). In contrast, people experience inauthenticity as an unpleasant emotion when they perceive incongruence with their values, goals, emotions, and self-meanings (see Gecas 1986, 1991, 1994). As an emotion with strong positive valence, authenticity plays an important positive motivating function for the self (Gecas 1986, 1991, 1994). For example, in his study of kitchen workers, Fine (1996) finds that chefs actively seek opportunities to maximize their work autonomy and minimize managerial interference in order to act in congruence with their culinary aesthetic standards and to feel good about their creative work. The suggestion that authenticity is 
always a pleasant feeling and inauthenticity is a negative one can be deceptive, however. If people could feel discrete emotions in isolation from other emotions and from the social consequences of their action, then perhaps authenticity and positive affect would be inevitably consequential. However, acting in congruence with oneself and feeling authentic may have its costs. At times, indeed, the costs of self-congruent conduct are so high that an individual may experience overwhelming sadness, stress, anger, and other negative emotions together with authenticity.

Despite the importance of the emotion of authenticity for self and society, it would be a mistake to state that people can feel fully authentic or inauthentic at all times in the same ways; rather, we all fall in between the two extreme poles and oscillate from one side of the continuum to the other at different times, in different situations. Authenticity and inauthenticity, therefore, are somewhat ideal types and people experience hierarchies of authenticities much as they experience hierarchies of identities. There are at least two reasons for this. First, many diverse and, at times, even contradicting meanings and values compose the self-concept and some are more significant than others for self-definition. Because different self-values and emotions are often competing in social situations, individuals feel authentic when their conduct is congruent with those emotions, meanings, and values that are significant for them (Erickson 1995). Therefore, it is possible for someone to act in opposite ways in different situations and yet to feel authentic in both circumstances. Second, individuals rarely enjoy complete autonomy in their social life. Instead, social agents need to enter processes of negotiation with themselves and others (Strauss 1978) and therefore settle for compromises of various sorts. Accordingly, even the construction of the sense of self and related authenticity is an artful process of crafting from locally available resources "all the while constrained, but not completely controlled, by the working conditions of the moment" (Holstein and Gubrium 2000:153). For example, for a university teacher who is a dedicated researcher, choosing whether to spend more time on giving feedback on undergraduate students' coursework or on editing a research paper driven by intellectual curiosity entails an act of negotiation between what is ethically desirable and what is personally desired. Opting for one or the other entails a complex process of negotiation that makes authenticity an ambivalent experience, that is, an emotion that can hardly ever be pure or "perfect."

The concept of authenticity has undergone much criticism in recent years, especially because of its connotation with modernism and modernity as a cultural and historical era (for a review, see Ferrara 1998; Holstein and Gubrium 2000). For example, Gergen (1991) suggests that the postmodern self is saturated with mediated realities, torn apart by conflicting social demands, overwhelmed by contradictory interpersonal relationships and obligations, suspended in a relative void of time and space, and incapable of finding one's own identity in a world of ephemeral meanings and evanescent beliefs. In sum, "the very concept of an 'authentic self' with knowable characteristics recedes from view. The fully saturated self becomes no self at all" (p. 6). But if we understand authenticity as a situational emotional experience 
rather than a condition of being, as pragmatists we should agree that what we feel is real to us under specific circumstances; real in its pragmatic consequences for the self (see Denzin 1984).

The social nature of the self is not a pre-emptive condition for the existence of authenticity. For example, for Cooley ([1902] 1964), reflected appraisals are not passive reflections of how others judge us, but instead, as Franks and Gecas (1992:51) point out in their assessment of Cooley's self-looking glass, are "our own conceptions about others' ideas of us." And for Mead (1934:199-200), too, "the individual is constantly reacting to the social attitudes, and changing in this co-operative process the very community to which he belongs." Indeed, it is precisely in acts of negotiation with one's social environment that one's agency-and therefore one's conditions for acting authentically — transpires (Erickson 1995). ${ }^{1}$ As Goffman (1961) explains, it is in the self's negotiation with others, even within total institutions, that secondary adjustments "provide the inmate with important evidence that he is still his own man, with some control over his environment" (p. 319). Additionally, it is within the person's choice to associate with significant others through which "our sense of being can come from being drawn into a wider social unit" (p. 320) that agency and the possibility for authenticity are manifested. However complex and ambivalent they may be, feelings of authenticity are real because emotions are real to the self and always "emerge[nt] within social acts" (McCarthy 1989:56; see also Schwalbe 1993).

\section{METHOD AND DATA}

The research question driving this study is how do faculty members at Mountain State University experience authenticity and inauthenticity in relation to teaching? My method consists of in-depth, semi-structured interviews with a purposive sample of forty-six faculty members employed at Mountain State University (fictitious name) during the academic year 2002-2003. I obtained lists of faculty members employed in three departments in each of three academic fields: the social sciences (psychology, political science, and anthropology), natural sciences (physics, chemistry, and biology), and the humanities (English, music, and philosophy), and divided faculty members into groups according to their rank. Then I randomly selected two names from each of the following three categories: assistant professor, associate professor, and full professor. Whenever a department employed limited term, part-time, or adjunct faculty (i.e., sessional instructors), I also included one such faculty member, randomly selected, in the sample. In the end, I interviewed a total of forty professors and six instructors, which is seventy-five percent of those contacted. Thirty-four participants were men. All participants but one (one Asianborn female) were of European (white) descent.

All interviews took place in each professor's own office or lab, and lasted from one to one-and-a-half hours. Mountain State is a mid-sized public university classified by the latest Carnegie classification system as a Doctoral/Research University- 
Extensive. Yet, at Mountain State some departments are clearly more nationally competitive than others, whereas some departments do not even offer doctoral degrees.

I began each interview by collecting general biographical and work-related information, such as marital status, age, length of employment at present and previous institutions, characteristics of present and previous appointments, etc. Subsequently, I asked faculty to tell me the story of how they chose their profession and probed them to find out about the values, goals, and meanings they give to their work and to their identity as professors, and how these have changed over time. Then, I asked participants two questions derived from Turner's True-Self Test (Turner and Schutte 1981), slightly modified in terminology from the original (one for authenticity and one for inauthenticity): "I'm very interested in understanding what it means to you to be authentic, or true to your self, in the context of your work. Can you tell me some personal stories of times when you felt that you were being authentic, true to your self, in the context of work, and in particular in the context of teaching? What was it about your experience on each of those occasions that made you feel you were true to your self?" The inauthenticity version was identical except for the substitution of "authenticity" with "inauthenticity" and "true" with "untrue." I followed up their responses by probing for elaboration and asking other follow-up questions related to teaching activities (e.g., personal and institutional goals, opportunities, limitations, pressures).

Because my conception of authenticity and inauthenticity is closely tied to emotions, open and focused coding of the transcribed interviews centered on linguistic indicators of professors' emotions of authenticity. In the majority of cases, this turned out to be a rather simple process because many informants explicitly made reference to what their "true self" was as they narrated stories of how they made the choice to become professors in their field and how such choices made them feel. Common indicators were such sentences or sentence fragments as "this is who I am," "I know myself and this is why I ...," "I wouldn't be true to myself if ...," "I feel most authentic when ...," and so forth. I constructed a schematic summary of professors' emotions by using thematic descriptors, and examined links to self-feelings in faculty's answers to the two questions derived from Turner's True-Self Test.

\section{The Context of Authenticity and Inauthenticity}

Before I examine the emotional qualities of the experience of inauthenticity, I wish to describe some of the structural and cultural dynamics that may make it difficult for some faculty to act in congruence with their sense of self. Attention to these structural and cultural dynamics allows us to focus on the "downward' shaping of the individual's emotions by culture, structure, and social institutions" (Franks 2003: 794).

At Mountain State, many professors have come to know that as teacherswhether tenure-track or not-they are basically irrelevant to their school. Policies originating at the level of federal and state legislatures affect the definition of the 
situation and interaction at the institutional level (Hall 1997) and shape the subjectivity and experiences of all Mountain State faculty members, thus limiting their opportunities to act and feel authentic. Interview data show that professors in particular identify two forces shaping their experiences, forces generally known by them as the ideology of "publish or perish" and "get grants or perish." These distinct but closely interconnected occupational ideologies are forms through which institutional power is manifested across different colleges, schools, and departments.

Simply put, "publish or perish" shapes professors' work by directing their energy toward conducting research and publishing in great volumes. At a research university, if a professor fails to publish he/she will perish professionally; in other words, he/she will not receive tenure, promotion, salary raises, or other perks. "Get grants or perish" is a somewhat newer institutional force. Professors have always needed to seek research grants (especially in the natural sciences), but over the last twentyfive years state budget crises have prompted state legislators to cut Mountain State's budget year after year, thus pushing university administrators to pressure their faculty into raising funds for the university (on this trend across universities, see Slaughter and Leslie 1997). Carl, an older associate professor in the natural sciences, clearly described how these forces have shaped his own work experience:

\begin{abstract}
At the beginning, the name of the game was "publish or perish," I'm sure you heard that. By the time I had been here for a while, the game had transformed into bring-research-money-or-perish. As an associate professor, I had three papers in the most prestigious journal in the field, and I still was not promoted. And that's because I did my work somewhere else and the money that was associated with my work was somewhere else. I worked on \$10 million experiments using $\$ 200$ million accelerators, but that didn't bring any money to the university.
\end{abstract}

Much like "publish or perish," "get grants or perish" works by rewarding professors who engage in funded research and by penalizing professors in fields where grant money is scarce or absent. As grant-assisted research endeavors become Mountain State's main priority, teaching and other activities become less important.

Although professors are openly aware of the practical segregation of teaching, the university continues to claim through its public advertising campaigns that excellence in teaching is the school's mandate and priority. For example, Mountain State University advertises itself through the slogan (slightly altered here to protect confidentiality of informants) "Global Leaders: One on One," used in state-wide and national campaigns. The message of "Global Leaders: One on One" is encoded with an ideology promoting the importance of teaching: "one on one" evokes notions of close rapport between professors and students, of individualized attention, care, dedication, and availability, and "global leaders" connotes that Mountain State faculty share high professional recognition, prestige, and status. Throughout my interviews, I asked professors to interpret the meanings of "Global Leaders: One on One" and I found that no professor believed in the truthfulness of this message. For Jim, associate professor in the natural sciences, the slogan is but a hypoc- 
risy because departments always fail to recognize good teachers and because the school puts bottom-line economics first:

The university is now run by a bunch of businesspeople and I think one of the situations that are now common is the issue of selling property, natural areas. For example, we have an area out on the countryside that has been used for a number of research projects, and now the university wants to sell that property or at least try and develop it in economic terms. ... In their eyes, they are useless research areas that bring no money and are often used by and for graduate student research. You know, the university is being run by bean-counters now. My view is that traditionally university administrators have been in charge of making research possible by finding the funds it takes. Now that responsibility has been turned to faculty members who are basically told: "if you want to do research, if you want technology, if you want advancement you need to bring in money into the university." Of course that also leads to publications, and of course professors who are doing well and having a nice career are professors who have multi-million dollar grants for research and some of these people are not very good teachers... So essentially we have two kinds of things going on here: we have the judging of the faculty along one criterion and we're telling the public about another criterion.

For Jim, the process of getting tenure had been emotionally very difficult. Early in his career, Jim had chosen to dedicate his research to a subfield of molecular sciences that over the years had traditionally suffered from lack of funding. After receiving numerous verbal pressures from his department to publish more research and to concentrate his research efforts on issues of close relevance to agricultural development, Jim had "given up" caring about research altogether five or six years prior to my meeting with him. As a consequence, he had been "relocated" to a new school within molecular sciences where he taught eight classes a year (instead of the one or two or three that his colleagues taught) and also spent a great amount of time on service and institutional governance-related tasks - such being traditional forms of punishment for perished tenured professors. When I asked him why he had never been promoted to full professor despite his long tenure at Mountain State, Jim remarked that despite being a good teacher and being fully committed to his students and to his vocational mission, he never received the recognition he deserved from the university, as the following excerpt summarizes:

I honestly feel that if you really put your heart into teaching you're not going to be rewarded for that. If you have a poor research record and you're the best teacher in the world, you're not gonna get tenure. It's a thankless portion of the job. I wish the university was honest about its priorities.

At Mountain State, tenured professors are labeled by their departments either "research-active" or "research-inactive." Research-inactive professors are assigned to teach a higher number of classes than their research-active colleagues. Researchinactive professors are often also associate professors who have never been promoted to the rank of full professors despite having worked there for up to thirtyfive years. Research-inactive professors, together with part-time, limited appointment faculty, are also often referred to as "teaching faculty." 
Different departments have different concentrations of research-active professors and "teaching faculty." Research-active professors are numerous in biology, chemistry, and physics. These professors conduct heavily-funded research and some of them also enjoy excellent international reputations. Nevertheless, many of these "global leaders" are completely uninterested in teaching one-on-one or in teaching at all, especially in undergraduate teaching. Instead, it is in the humanities, where funds and prestige are much lower, that one-on-one education truly takes place. Consider for example the case of Judi:

INTERVIEWER: "Global Leaders: One on One"; what does that mean to you?

JUDI (associate professor, humanities): [Laughs] Well, I know every student here. I know everybody in my choir. When it comes to letters of recommendation they ask me, even if they're in chemistry or physics. I know my students, I know their background, sometimes I know their family. We teach one on one. We have great faculty but we have a very small budget to make our faculty's impact truly global.

Judi's comments suggest that Mountain State University's slogan is not a lie, but instead a constant reminder of the structural inequalities of academic work and an example of how workers' emotions and identities are shaped by organizational constraints (see Schwalbe et al. 2000). For Frank, as well, an English professor, Mountain State's slogan connoted institutional injustice and inequality. For him, the rhetoric of "Global Leaders: One on One" represents the marginalization not only of those professors who dedicate themselves to teaching and/or unfunded research, but also of entire fields and sub-disciplines.

Furthermore, Frank explained that the humanities cannot compete for funding with the natural sciences, and as a result their sheer survival is in danger. The work of the professoriate in these departments is informed by, as professors put it, the CYA and JYE modus operandi: "Cover Your Ass" and "Justify Your Existence." Both CYA and JYE refer to the need that professors have in the humanities to continuously show proof of their relevance in order to justify both their own employment and the very existence of their department in the face of their status as alleged financial liabilities. CYA and JYE call for carefully documenting every aspect of work in order to defend one's employment whenever asked to justify it. Music professors, for example, are credited with teaching hours and performance hours outside the classroom, but the university has a tendency to dismiss these activities as a voluntary service rendered by professors out of the goodness of their heart, as Judi explained:

If you did it for the money you wouldn't do it for the passion. But we have to be careful. Music can be seen as a service. Whenever we have people coming in to visit the university, or for commencement, people like to have some entertainment, so they go "let's call music!" And they do call us and ask us to perform. And it kind of reminds me of church service, when I was a kid, or even when I was in college. People want music at the service in church, but do they think they should pay you? No! "That's your service, that's your gift, so we don't pay you, 
that's your gift to God!" That's the kind of attitude you deal with in music. And in many ways it is the same here, where we get this attitude: "What, you mean you want to be paid too?"

The situation is very similar in the English department, where Professor Julian explained that an extramural grant is practically impossible to obtain, given the very small budget of the National Endowment for the Arts and Humanities. In order to justify its existence, the English department is made responsible for training (or better yet, re-training) undergraduate students to write in proper English. But for Julian, "funding literacy is only a token interest":

Since the Reagan era, funding for the humanities is not existent. So we can't compete with folks in the sciences. Part of being able to get million dollar grants is by providing a line of information that is of interest to the state. Funding literacy is only a token interest. And there is the conception that it is only an amateur field. In other words, if you can read and write, you can teach reading and writing, anyone can. There is also the perception that most of the work of an English department is literary criticism, and that literary critics are parasites that exist on the talents of others. So funding for us is not an option. What keeps us alive is the literacy needs of the university as a whole.

But the true interests and mission of the English department are not in composition, but elsewhere. Mountain State English professors and graduate students are the most politically progressive and active on campus. Their radical oppositional ideologies and everyday politics have pitted them over the years against both university administration and the state and federal administration. What is at work in their department - in Julian's and colleagues' interpretation-is an alternative ideological frame, though "Global Leaders: One on One" connotes nothing but an attempt at the colonization of the lifeworld of professors, students, and taxpayers:

The state won't pay for rhetoricians. There's no money there. But in figuring out how to get an atom to explode as it's going through a lot of dirt and getting 1200 feet underground, oh yeah, that's the big one. I just heard that one yesterday on the news. But look, in order for the state to survive, to continue to do what it does, it needs to maintain the consensus of the people. So it's funny that they don't recognize that the greatest weapon must be communication. And so the school is affected in two ways by this current political climate. One is in the budgets and funding being cut. And two is in the students who now come to the classroom and see themselves as consumers and make the demands that are typical of consumers, and education becomes compromised in the process. (Julian, professor, humanities)

In Julian's mind (and others in the interpretive community of the humanities, as well), the greatest majority of students/consumers come to Mountain State University not for a liberal education, but rather for a piece of paper that works as a passport to obtaining a job. These students/consumers demand not a critical political consciousness, but a narrow education that will allow them to be qualified enough for a job, a career, or a trade. Some of these conditions, as we will see in the next section, are at the origin of experiences of inauthenticity. 


\section{THE EXPERIENCE OF INAUTHENTICITY}

\section{Authenticity Inherent to Teaching Practice}

Teaching is a source of at least two different types of inauthenticity. The first type is inherent to teaching itself (or at least to the general pedagogy of teaching typical of higher education in Western society). For example, teaching-at least in conventional universities like Mountain State-demands that professors assign students marks on their assignments and exams. Marks, however, are similar to money in the sense that the most valued currency (A) must be assigned parsimoniously, lest it lose value. Many departments even set specific policies to avoid "grade inflation" by limiting the number of students who can receive As, Bs, Cs, and so forth. By doing so, universities manage to maintain an image of fairness and seriousness in the eyes of current and prospective students, but at the same time they limit professors' discretion in judgment. Because I value fairness and because I think of myself as a fair and just person, I feel deeply inauthentic whenever I need to excogitate ways of justifying assigning a B to a student who deserves an A. Not only am I lying to students, but I also feel that I am lying to myself. Many Mountain State professors also feel that the ideology of grading causes them to compromise their values. Robert, an instructor in the natural sciences, experienced the sharp sting of authenticity when he compromised his own integrity in assigning a mark higher that what he perceived to be fair:

I had one experience when a student came in with a $\mathrm{C}-$. It was a borderline grade and he was trying to negotiate for a higher grade because that was his last semester and there was an issue of a scholarship involved or whatnot. I talked about it with my colleagues and found out he had failed the class before and this was his last semester and was not planning on coming back. So I gave him a higher grade. And a few months later I found out that he had benefited from that to get into nursing school. I felt like shit. I had betrayed my sense of fairness, and I had basically lied to my colleagues in the nursing school.

Robert is not the only one who occasionally yields to student pressure. Mountain State professors find "grade-begging" to be a common occurrence and to cause-in addition to the occasional experience of inauthenticity-stress, annoyance, and antipathy toward students. Grade begging can also be a source of inauthenticity when the overachieving student altercasts (Weinstein and Deutschberger 1963) the professor into a role that violates his/her values. Grade begging makes me feel inauthentic. When a student comes into my office and asks for an A- instead of a B+ I am no longer an educator. By begging me, the student defines the situation as something other than a learning environment. As I am implored, I cease to be a teacher in the student's eyes as well as in my own experience of my identity, and I become a banker, a loan shark, and a means toward an end (higher grades, rather than knowledge) that I do not value.

There are other aspects inherent to teaching that cause professors to feel inauthentic. For example, Bryan values the depth of academic knowledge, and as a 
philosopher he is well aware that human existence is too complex to be broken down into the true-or-false statements that introductory-level students want to be given in order to do well on tests:

I feel inauthentic all the time this semester, because in 101 and in introductory level classes I have to get up and teach off the textbook every day, and so I have to give them an abbreviated version of a very complex thing, so it's sort of like a lie that I'm telling them. So it's not bad information but it's not the whole story. I can feel more authentic in graduate courses because we have more time and we can explore issues in more depth. (Bryan, assistant professor, humanities)

There is an important difference between sincerity and authenticity. Sincerity is the act of being truthful to others, whereas authenticity is the experience of being true to oneself (Trilling 1972). Bryan, in this case, is feeling a bit of both. Whenever this occurs, self-feelings such as guilt and shame may be experienced together with inauthenticity.

\section{Frustrated Authenticity}

The second type of inauthenticity associated with teaching is frustration, or frustrated authenticity. This type of inauthenticity is not inherent to teaching, but is instead typical of an institutional structure and culture affected by the changes examined throughout this article. Frustrated authenticity is not a case of inauthenticity proper. Rather, along the continuum of authenticity and inauthenticity, frustrated authenticity falls somewhere down the middle, functioning much like a road block to authenticity. Frustrated authenticity is the experience of feeling ineffectual in the attempt to be congruent with one's values. Frustration, as an emotional experience, means feeling thwarted, foiled, baffled, and balked. People feel frustrated whenever their plans for goal-achievement are defeated because of the presence of obstacles or hindrances (Janis 1971). In a sense, the emotional experience of frustration is a testament to the power of physical and social structures to limit individuals' choice and action. For example, Emily felt the experience of frustrated authenticity whenever she could not dedicate enough time to the achievement of her pedagogical goals:

I feel most frustrated when you walk into a class and you're not prepared, and you're really stretching it out just to get a way out of there. You know, when you really go in and try to wing it, that's when I don't feel good about myself. It happened to me recently and I walked out of class and I asked myself, what the hell am I doing? (Emily, associate professor, social sciences)

Emily explained that the forces of "publish or perish" and "get grants or perish" make it impossible to set aside time for class preparation. Emily is committed to teaching, but because of structural costs and limitations associated with her goals and values she is thwarted in her attempt to pursue authenticity.

Other professors undergo experiences similar to Emily's. Many professors in the humanities and social sciences feel that what they value-knowledge and education, social emancipation, political responsibility, democratic pedagogy, etc.-is not 
valued by the university. This difference in personal and institutional values translates into a variety of behaviors and dispositions. At times, professors "rebel" against institutional forces and authentically dedicate themselves to teaching, taking great pride in "being against" the institution that employs them; at other times, however, these secondary adjustments bring emotions other than pride (Goffman 1961). Consider, for example, the case of Kathryn:

You know, with the school the way it is, sometimes you really take great satisfaction or pride in saying "fuck it! I'm tired of chasing the money trail; my students need me and I'm gonna give them the education I want to give them." Like we were saying, that makes you feel really good, really authentic, you know. But there are other times when acting is not going to make you feel good. I mean, sure there is a part of you that says "Kathryn, you're being true to yourself, and that's good, or whatever," but there is another side of you that feels different. And it's almost like this other side is stronger in those moments. And that side is not a feeling of authenticity, but almost something like alienation. (Kathryn, associate professor, social sciences)

Kathryn's emotional experience of alienation (on this, see Schwalbe 1986) is particularly interesting because it shows that acting in congruence with one's values is not always associated with pleasant feelings. This is not because authenticity is a negative emotional experience in those cases, but because at times the costs of acting authentically are so high that negative emotions outweigh the otherwise positive experience of authenticity. At Mountain State, such experiences were common in the social sciences and less in the humanities. In the social sciences, professors need to cope with a Janus-faced institutional culture that strongly emphasizes research and an occupational ideology that stresses the importance of socio-political emancipation. Interestingly enough, for people like Kathryn who have tenure, saying "fuck it!" presents fewer costs than it would to an untenured professor. Indeed the emotion of authenticity has a price, a price that makes its experience ambivalent and variable in degree from experience to experience.

Lack of time is the main cause of frustration among Mountain State professors. The forces that push professors to dedicate more time to research than teaching tend to make goal-achievement and value-congruent conduct problematic for those who are committed to teaching. And because teaching is rewarded far less than research, other professors experience teaching as a burden. When teaching is perceived as a burden-because it takes time away from activities that professors value more, such as research-time spent in the classroom becomes a source of frustrated authenticity for professors like John:

The negative aspect of teaching is time. There is no time for teaching. Let's not joke ourselves; this is a doctoral institution. Teaching takes times away from research. (John, associate professor, natural sciences)

It would be a mistake to suggest that the ideologies of "publish-or-perish" and "get-grants-or-perish" are causes, however indirect, of the frustration that professors like John experience. Of course, these forces play an important factor in facilitating 
the conditions of frustrated authenticity, but there is also a dynamic of self-selection at play. Because Mountain State is a research university, it tends to attract academics who value research more than teaching. These conditions and phenomena are especially true in the natural sciences. Time for teaching is especially scarce in the natural sciences. In the natural sciences (and to a lesser extent in the social sciences) where professors mostly think of themselves as researchers, teaching is often perceived not only as a source of frustrated authenticity, but also of boredom or apathy:

I'm no longer fascinated with teaching. Teaching tends to be the same thing over and over. The reinforcement that you get from teaching does not compare very well with the reinforcement that you get from doing research, and I mean, the recognition that you get from colleagues in your field. The pleasure comes from both discovery and recognition in research. In teaching there is nothing I value. It just makes me feel like I'm wasting time. (Patrick, professor, natural sciences)

The last emotional experience accompanying inauthenticity that I wish to examine is disdain - a much-neglected emotion in the research literature (for an exception, see Darwin 1872). Disdain is a feeling of contempt, disparagement, or scorn for something or someone that people hold to be beneath themselves. Disdain is also related to empathy. Whenever there is disdain, there can be no empathy-an emotion that often accompanies authenticity for those professors who are committed to teaching. Disdain in itself is not a condition of inauthenticity, but because professors cannot display their disdain to students, inauthenticity at times arises as a result of the emotional labor needed to repress it (Hochschild 1983). A professor in the social sciences, for example, once had to restrain herself from the emotional outburst she felt she was entitled to when a student in class commented on the Rwandan genocide: "Who cares if a million of them died? They're all African, anyways!" Professionalism has feeling rules that can be quite inauthenticating (Hochschild 1983).

Professors' disdain for students is most often not inherent in the practice of teaching. Rather, much disdain seems to be caused by recent structural and cultural changes in higher education. Universities are currently facing the need to offer a service designed with the demands of its customers (the students) - and not of its producers (the faculty) - in mind (Levine 1997). Universities must now educate students who are primarily interested in a university diploma as a means to obtaining a job in the economic market:

I can't stand teaching, especially with the kinds of students here. [. . .] The students don't take it seriously. It's a miserable experience. They don't think they have to do any reading. It is hell of a lot of work and it's so depressing how cynical students are and how much time they spend avoiding any intellectual activity, and how much we're expected to entertain. I'm not an entertainer, I'm a scholar and I never get to talk about the research I do. They look at you and they go "who is this person?" There is no sense of who you are and what you do, there is no respect. They're rude. And I don't want tell them what to do and how to behave. I'm not a policeman, I'm not a socializer, I'm not their mother, and it's a horrible position I'm in, and I have to compromise with them and with myself and I don't want to, and I hate it. (Erika, professor, social sciences) 
The compromise that Erika mentions is source of inauthenticity because in violating her preferred pedagogy she violates her sense of true self as a teacher. Erika's disposition toward her students is clearly one of disdain, an emotional experience especially common in the social sciences. In fact, Mountain State professors' attitudes toward students are highly variable across departments. Professors in the humanities have high opinions of their students, whereas professors in the natural sciences generally manage to establish closeness (whenever they do) with only a few talented upperclassmen that they often hire as lab assistants. Mountain State professors in the social sciences, instead, seem to struggle establishing a sense of collective identity with their students. The case of political science is a good example of the gap between students mostly interested in crime and correction as a means of getting a job with the state police, the FBI, or similar agencies, and faculty generally interested in larger comparative, socio-historical, and political trends.

In conclusion, professors' emotional experiences of inauthenticity are often related to changes in the structure and culture of higher education. Some experiences of inauthenticity are instead inherent in the practice of teaching itself, given the educational model adopted by most institutions in Western societies. Inauthenticity, as professors experience it, often comes hand in hand with emotions such as alienation, disdain, frustration, and boredom.

\section{The Experience of Authenticity}

As the highly critical individuals that we are, academics complain a lot; however, teaching university students is also a source of many experiences of authenticity. I recall with great pleasure receiving an e-mail from Anne in the fall of 2004. Anne was an older, distance-education student living in an isolated community in the prairies of Canada. She had left school early in her youth, and coming back to college in her mid-forties had turned out to be an epiphany for her. My class on media and culture had particularly been enlightening for her new sense of self and identity. "I can't believe I'm actually able to read a book like the one you gave me," she confided to me. "Now I can actually watch the news on TV and make intelligent comments. I surprise my kids and husband every day, these days," she continued, "and I now feel that my kids can come talk to me about things other than their midafternoon snacks and their dirty clothes, and I want to thank you for inspiring me to believe in myself and think critically about what's around me." These words still bring tears to my eyes. Rarely have I ever felt so much pride in the accomplishment of a faceless stranger. With her, I had kept my promise to myself: to inspire and to stimulate a sense of confidence in students. I felt true to myself, and I felt a sense of achievement and satisfaction, as well as much shared joy in a true peak moment of authenticity.

The experience of authenticity generally comes in the form of a peak or a plateau. Peak experiences of authenticity are sudden, brief, more emotionally intense, purer, and more powerful in their potential to inspire self-change. Plateau experi- 
ences, instead, are placid, longer-lasting and often marked by such feelings as contentment, satisfaction, serenity, and inner peace. Within a musical metaphor (Vannini and Waskul 2006) peak experiences resemble sharp tone colors and quick shifts in the rhythm and melody of life. Plateau experiences share with musical arias the bliss and tranquility of mid-frequency pitch and smooth sounds. For Mountain State University teachers, peak experiences of authenticity are more common than plateaus.

For Mountain State professors, experiences of authenticity in the context of teaching are relatively infrequent but not nonexistent. Mountain State is a research university and teaching is for most a nuisance and a source of inauthenticity. Nevertheless, some professors strongly value their identity as teachers. The professors that were interviewed assign teaching such values as political and moral responsibility, social equality (achieved through intellectual emancipation), freedom of thought and speech, and creativity. But even though a robust majority of Mountain State professors stated that in principle teaching is an important component of their role as professors, only a minority of them admitted that in actuality they cared a great deal about being a teacher. Hence, only for a minority of them were teachingrelated values meaningful for their sense of true self.

\section{Empathy and Authenticity}

For those professors who cared about educating students, feelings of authenticity occurred whenever they felt empathy with others. Empathy is an emotional state marked by a feeling of understanding and awareness of others' emotional states (Eisenberg 1989; Kohn 1990). Feeling empathic, as well as authentic, means feeling true to one's will to connect to others; to be sensitive to the feelings, thoughts, and experiences of someone. Much as I felt empathy with Anne through her self-discovery, Mountain State professors who feel true to themselves in the realm of teaching, advising, mentoring, and helping students in general feel that what gives meaning to their work is, in part, the power and ability to be in a community of shared interest with their students. For example, Frank, an assistant professor in music who decided to abandon his singing career to be closer to students, explained that he feels most authentic when he can hear and feel his self in his students' voices.

Frank is not alone in feeling authentic by inspiring, and by forming a connection with, students. Many professors across ranks and departments explained that the most authentic component of teaching is the possibility to be useful for students, to make a difference in their lives, and to be successful at educating, at least in small part, young people. Professors experience authenticity, in this sense, together with the feeling of empathy as well as self-efficacy, which refers to the "perception of oneself as a causal agent in one's environment, as having control and being able to control one's circumstances" (Gecas 2001:93). The following excerpt is typical of experiences of authenticity in the context of teaching:

My goal at this point is to continue to make contributions to the field. And to do a good job at prepping graduate students to enter their careers. It's more gratify- 
ing for me to hear that a graduate student of mine has been accepted into the graduate school that he wanted to get into, than to get a letter in the mail that says "your paper has been accepted." For example I had a female student last year who wanted to get into the graduate program at a prestigious university and she thought that she had no chance whatsoever. It turns out that she called me on a Sunday, at home, and she said to me "I was just on the phone with them and they accepted me into their program!" and she was incredulous that this had happened. That's a lot better than a publication. At this point in my career that's more gratifying. (Rick, associate professor, social sciences)

For Rick, the powerful feelings connected with empathy and self-efficacy were even more important than those associated with egoistic individual success and personal achievement. Stereotypically, one would expect female teachers to be better able to empathize with students and perhaps even to feel more authentic within the realm of teaching than that of research, at least compared to their male colleagues, but my data analysis does not support this gendering of authenticity. The emotions of empathy and self-efficacy were also equally common for men and for women.

My data analysis shows the presence of differences, however, in relation to the objects of one's empathy. Mountain State professors find it more common to experience authenticity when relating to graduate students, as opposed to undergraduates. Because Mountain State is a research institution, professors seem to be more at ease at taking the role of graduate students as they "see more of [themselves] in graduate students, and feel less in common with undergraduates," as one professor put it. Another professor remarked,

A great example of authenticity is when you see a graduate student whose "light" clicks, when you know that what you're doing is making a difference outside of your brain. (Nigel, assistant professor, social sciences)

Professors establish closer emotional connections with graduate students not only because they share with them a sense of collective identity, but also because they feel that their emotional relationship with graduate students is not vitiated by the instrumental logic of grading. "It is difficult to feel certain that what you have done has truly made a difference," a professor explained, "when perhaps all the positive things that you see are just ways that the student has of sucking up to you to get a better mark." It is just as difficult to be certain of one's self-efficacy when one's teaching may only have sunk as deep into a student's soul as a perfect score on a quiz. Experiences are different with graduate students. On one hand, inspiring graduate students is indeed, in the words of April, "like preaching to the choir"; on the other hand, professors can share with graduate students the pathos of a common career path. For example, when the only graduate student I ever supervised received news of her first publication-a paper on which I spent a great deal of unpaid time-I felt able to intuitively know what it was like for her to achieve that kind of success. And of course I felt that I had kept my deeply-felt promise to help students. My feeling of authenticity was mixed with sentiments of magnanimousness, nobility, and-as one Mountain State professor said to describe her own feelings 
under similar circumstances_- "a certain sense of pride and personal satisfaction in being generous, in such an individualist culture, and in the cutthroat world of academia."

Of all faculty ranks, those who feel most often authentic about their teaching are sessional instructors (i.e., adjuncts, or nontenure-track teaching faculty; on this body of scholars, see Leslie 1998). The majority of instructors I interviewed had willfully chosen to stay away from a research or tenure-track position in order to dedicate themselves fully to their pedagogy and commitment to teaching. These Mountain State instructors stated they enjoy having the time to prepare for class adequately and to dedicate themselves to students' questions and requests:

\section{Students often come back and ask for letters of recommendation. I'll write fifteen-twenty letters of recommendation a month. And it's nice, because I get to know them. It's a great service to both the students and their potential em- ployers. Also I do a science camp every summer. It's a week long. It's for six- eight year olds and I get them interested in science and interested in going to college. So hopefully the idea of getting to these six to eight year olds will inspire them. (Bruce, instructor, natural sciences)}

Having more time for teaching allows instructors to be fully congruent with their commitment to the values of teaching. Mountain State instructors believe that education is important and that undergraduate students do not deserve to be treated like a nuisance. Instructors also are quite critical of their research-active colleagues, who, according to them, could not care less about improving labs, interacting with students in introductory-level classes, grading, and answering students' queries. Instructors believe that teaching is pleasant and self-fulfilling work, and even leisurethus confounding the boundary between the two as Stebbins (2004) has shown to be typical of certain occupations, such as the "vocation" of university faculty-rather than a time-consuming chore:

I come in, I work my hours, sometimes it's nine and sometimes it's ten. I work a lot for my classes. I re-invent a lot of courses, I spend weeks choosing textbooks, I have websites for all my courses. I am writing a lab manual this summer. Not that I get paid any more by teaching better, but I just want to do better. (Steve, instructor, natural sciences)

The scenario is not too dissimilar in the humanities. I found the most dedicated teachers in English, philosophy, and especially music - teachers who see teaching as intriguing, interesting, creative, and engaging kind of work. Some music professors even admit feeling inauthentic when they are away from the classroom for too long, because they invest so much of their emotional energy and identity into developing their students' skills:

I enjoy classroom teaching, I find it intriguing. ... I love working with individuals to create one kind of idea about music, one common idea ... I was on sabbatical last semester, and I missed teaching ... it killed me not to be teaching. (Pat, associate professor, music)

Music faculty members believe that it is especially important for them to feel authentic in the context of teaching because of their heightened aesthetic sensibilities. 
"You can't lie with your music," a professor said, suggesting that the musical connection between student and teacher must be genuine and sincere, or else music will not be aesthetically pleasing to their senses. Just as Frank, whom I mentioned earlier, is able to connect to students through sound, other music professors experience their feelings of authenticity, together with a sense of aesthetic pleasure, in ways not too different from what chefs feel in their work (Fine 1996). These professors experience authenticity together with a feeling of creative self-fulfillment:

I like the freedom that we have in what we are allowed to do as faculty. First of all, working with the students who are somewhat intellectually mature and know what they want to do. Second, working with students who are developing musically. We can take them from a certain level and take them to the next level. Then, I feel that my mission is in teaching and that teaching is important despite the culture of the university. And finally to be creative. (Danielle, assistant professor, music)

The emotional experience of authenticity is also often colored by sentiments of civic engagement and the feeling of justice. This is especially common for social science professors, who place much emphasis on critical political emancipation, both in their teaching and self-values. For one professor in the social sciences, feelings of authenticity were mixed with the emotion of justice anytime she recognized that one of her female students had become able to recognize the injustices of patriarchy. I, too, often feel authenticity mixed with a sense of justice anytime my media and culture students seem to recognize the ideological dimensions of much of our standardized and commodified popular culture.

In sum, for Mountain State professors, the emotional experience of authenticity is always accompanied by other emotional qualities. Feeling true to one's self, I suggest, is a complex and multidimensional self-feeling often marked by parallel emotional experiences, such as empathy, self-efficacy, pride, aesthetic pleasure and creativity, generosity, and justice. Nevertheless, for all such experiences to take place, teachers need to be personally committed to a variety of values and meanings they associate with teaching. That personal commitment can be understood as a form of existential care. As people invest energy in caring about certain strands of their self and certain aspects of their world, they emotionally open up to the possibility of authenticity. For the professors and instructors interviewed, caring about their beingin-the-world brings not only validation via authenticity, but also the feeling that one's self is meaningful and real to them. Understood this way, care is at the root of the experience of authenticity and at the root of the experience of self. In the words of Frank, the music professor, feeling authentic means "to care about something greater than yourself and greater than other people too, that is, to care about the very act of caring."

\section{CONCLUSION}

In this article, I have argued that authenticity, understood from a phenomenological and social psychological perspective, is a complex and often ambivalent emotional 
experience. My analysis suggests that professors feel inauthentic whenever they do not or cannot act in congruence with their values, emotions, goals, ideals, or, in general, with all that is meaningful to one's self. My interpretation also suggests that the emotional experience of authenticity is highly heterogeneous, as people often experience it together with other emotions, such as empathy, self-efficacy, justice, pride, as well as aesthetic and creative pleasure. Additionally, I suggest that when professors experience inauthenticity, they also often feel emotions of disdain, boredom, and alienation. Frustration, or frustrated authenticity, is somewhat of a different experience than inauthenticity, per se. Furthermore, interviews with faculty members highlight that the experience of inauthenticity is often associated with structural limitations that make the outcomes of acting in congruence with one's self costly or infeasible under certain circumstances. Although at times the experience of authenticity is relatively unaffected by structural changes (indeed, professors narrated instances of inauthenticity "inherent" to the very nature of teaching), my research shows that there exist important links between occupational structure and culture, and experience of authenticity and inauthenticity.

Even though Mountain State's ideologies of "publish or perish" and "get grants or perish" undoubtedly play an important role in limiting professors' choices and structuring their conduct, professors' experiences of authenticity and inauthenticity are not determined by any such structural forces. If there is a "managed heart" (Hochschild 1983) at work within the structure and culture of the university, then the very act of "managing" cannot escape our analytical consideration. Indeed, professors, no matter where their values lie (in teaching, research, or elsewhere), maintain the power to negotiate (Strauss 1978) among competing hierarchical systems of values, goals, and emotions; and it is such process of negotiation that we must carefully consider in order to understand the heterogeneity of the emotional experience of authenticity and inauthenticity. It is in this sense that my conceptualization of authenticity differs sensibly from Hochschild's somewhat deterministic approach to emotional labor and feeling rules. And it is in this sense-positing authenticity as will-that I am arguing for the importance of considering self-feelings as social forces (Erickson 1995; see also Gecas 2001).

Erickson (1995) has suggested that self-congruent conduct can generally be explained by referring to hierarchies of identity-salience. If an academic, for example, is committed to her identity as a teacher she will dedicate herself to teaching even though such authenticating course of action may endanger her career. My analysis of interview data collected for this study corroborates such a theory. Nevertheless, arrays of costs and opportunities for each individual course of action greatly complicate the picture. I, for example, admittedly care more about being a successful researcher than a successful teacher. My hierarchy of values, however, is not easily clear-cut. At times I feel compelled to spend time helping out a student even though I am more committed to some ongoing research project that needs my immediate attention. Why? Because on those occasions guilt, or similar emotions, push me to act inauthentically (because I do feel that way when sacrificing my research) and 
authentically (because I do care about that student, after all) at the same time. That is why we should understand negotiation as a complex act of care of the self-an act that demands we select among competing values, meanings, and emotions-and consequently, a process that results in the complex heterogeneity of emotional experiences such as authenticity.

Acknowledgments: The intellectual assistance, counsel, and advice of Viktor Gecas have made this work possible and I cannot thank him enough. I would also like to thank Simon Gottschalk and the anonymous reviewers of Symbolic Interaction.

\section{NOTE}

1. Despite the social nature of the self, we should not forget that an individual may experience authenticity when alone and distant from others, or in the company of nature. I thank one anonymous reviewer of this article for bringing this point to my attention.

\section{REFERENCES}

Altbach, Philip. 1997. "An International Academic Crisis? The American Professoriate in Comparative Perspective." Daedalus 126:315-38.

Altbach, Philip, Robert Berdhal, and Patricia Gumport, eds. 1994. Higher Education in American Society, 3rd ed. Amherst, NY: Prometheus.

Blumer, Herbert. 1969. Symbolic Interactionism: Perspective and Method. Berkeley: University of California Press.

Boyer, Ernest. 1990. Scholarship Reconsidered: Priorities of the Professoriate. Princeton, NJ: Carnegie Foundation for the Advancement of Teaching.

Cooley, Charles H. [1902] 1964. Human Nature and the Social Order. New York: Scribner.

Darwin, Charles. 1872. Expression of the Emotions in Man and Animals. London: John Mountain Staterray.

Denzin, Norman. 1984. On Understanding Emotion. San Francisco: Jossey-Bass.

Douglas, Jack. 1977. "Existential Sociology." Pp. 3-73 in Existential Sociology, edited by J. Douglas and J. Johnson. New York: Cambridge University Press.

Douglas, Jack and John Johnson, eds. 1977. Existential Sociology. New York: Cambridge University Press.

Eisenberg, Nancy, ed. 1989. Empathy and Related Emotional Responses. San Francisco: JosseyBass.

Ellis, Carolyn. 1991. "Sociological Introspection and Emotional Experience." Symbolic Interaction 14:23-50.

Erickson, Rebecca. 1991. When Emotion Is the Product: Self, Society, and (In)Authenticity in a Postmodern World. Ph.D. dissertation. Washington State University, Pullman, Washington. .1995. "The Importance of Authenticity for Self and Society." Symbolic Interaction 18:12144.

Farberman, Harvey. 1989. "The Sociology of Emotion: Feedback on the Cognitive and A-Structural Biases of Symbolic Interaction.” Pp. 271-88 in The Sociology of Emotions: Original Essays and Research Papers, edited by D. Franks and E. D. McCarthy. Greenwich, CT: JAI Press.

Ferrara, Alessandro. 1998. Reflective Authenticity: Rethinking the Project of Modernity. New York: Routledge. 
Fine, Gary Alan. 1996. Kitchens: The Culture of Restaurant Work. Berkeley: University of California Press.

Franks, David. 2003. “Emotions.” Pp. 787-809 in Handbook of Symbolic Interactionism, edited by L. Reynolds and N. Herman-Kinney. Walnut Creek, CA: AltaMira.

Franks, David and Viktor Gecas. 1992. "Autonomy and Conformity in Cooley's Self-Theory: The Looking Glass Self and Beyond." Symbolic Interaction 15:49-68.

Gecas, Viktor. 1986. "The Motivational Significance of Self-Concept for Socialization Theory." Advances in Group Processes 3:131-56.

1991. "The Self-Concept as a Basis for a Theory of Motivation." Pp. 171-88 in The SelfSociety Dynamic: Cognition, Emotion and Action, edited by J. Howard and P. Callero. Cambridge: Cambridge University Press.

1994. "In Search of the Real Self: Problems of Authenticity in Modern Times." Pp. 139-54, Self, Collective Behavior, and Society: Essays Honoring the Contributions of Ralph H. Turner, edited by G. Platt and C. Gordon. Greenwich, CT: JAI Press. 2001. "The Self as a Social Force." Pp. 85-100 in Extending Self-Esteem Theory and Research: Sociological and Psychological Currents, edited by T. Owens, S. Stryker, and N. Goodman. Cambridge: Cambridge University Press.

Gergen, Kenneth J. 1991. The Saturated Self: Dilemmas of Identity in Contemporary Life. New York: Basic Books.

Goffman, Erving. 1961. Asylums. Garden City, NY: Doubleday Books.

Golomb, Jacob. 1998. In Search of Authenticity: From Kierkegaard to Camus. London: Routledge.

Gould, Eric. 2003. The University in a Corporate Culture. New Haven, CT: Yale University Press.

Hall, Peter M. 1997. "Meta-Power, Social Organization, and the Shaping of Social Action." Symbolic Interaction 20:397-418.

Hochschild, Arlie. 1983. The Managed Heart. Berkeley: University of California Press.

Holstein, James and Jaber Gubrium. 2000. The Self We Live By: Narrative Identity in a Postmodern World. New York: Oxford University Press.

Janis, Irving L. 1971. Stress and Frustration. New York: Harcourt Brace.

Kohn, Alfie. 1990. The Brighter Side of Human Nature: Altruism and Empathy in Everyday Life. New York: Basic Books.

Kotarba, Joseph and Andrea Fontana, eds. 1984. The Existential Self in Society. Chicago: University of Chicago Press.

Kotarba, Joseph and John Johnson, eds. 2002. Postmodern Existential Sociology. Walnut Creek, CA: AltaMira.

Leslie, David, ed. 1998. The Growing Use of Part-Time Faculty: Understanding Causes and Effects. San Francisco: Jossey-Bass.

Levine, Arthur. 1997. "How the Academic Profession Is Changing." Daedalus 126:1-20.

Lyman, Stanford. 1981. "The Politics of Anger: On Silence, Ressentiment, and Political Speech." Socialist Review 11:55-74.

Manning, Peter. 1973. “Existential Sociology.” The Sociological Ouarterly 14:200-25.

McCarthy, E. Doyle. 1989. "Emotions Are Social Things: An Essay in the Sociology of Emotions." Pp. 51-72 in The Sociology of Emotions: Original Essays and Research Papers, edited by D. Franks and E. D. McCarthy. Greenwich, CT: JAI Press.

Mead, George Herbert. 1934. Mind, Self, and Society. Chicago: University of Chicago Press.

Rhoades, Gary. 1998. Managed Professionals: Unionized Faculty and Restructuring Academic Labor. Albany, NY: SUNY Press.

Schwalbe, Michael. 1986. The Psychosocial Consequences of Natural and Alienated Labor. Albany, NY: SUNY Press.

. 1993. "Goffman against Postmodernism: Emotion and the Reality of the Self." Symbolic Interaction 16:333-50.

Schwalbe, Michael, Sandra Holden, Doug Schrock, Douglas Thompson, and Michele Wolkomir. 2000. "Generic Processes in the Reproduction of Inequality: An Interactionist Analysis. $\underline{\text { So- }}$ cial Forces 79:385-418. 
Shibutani, Tamotsu. 1961. Society and Personality: An Interactionist Approach to Social Psychology. Englewood Cliffs, NJ: Prentice-Hall.

Slaughter, Sheila and Larry Leslie. 1997. Academic Capitalism: Politics, Policies, and the Entrepreneurial University. Baltimore, MD: Johns Hopkins University Press.

Smith, Charles. 2000. Market Values in American Higher Education. Lanham, MD: Rowman and Littlefield.

Stebbins, Robert A. 2004. Between Work and Leisure: The Common Ground of Two Separate Worlds. New Brunswick, NJ: Transaction.

Strauss, Anselm. 1978. "A Social Worlds Perspective." Studies in Symbolic Interaction 1:119-28.

Sykes, Charles J. 1988. ProfScam: Professors and the Demise of Higher Education. Washington, DC: Regnery Gateway.

Tiryakian, Edward. 1962. Sociologism and Existentialism. Englewood Cliffs, NJ: Prentice Hall. . 1968. "The Existential Self and the Person." Pp. 69-88 in The Self in Social Interaction, edited by K. Gergen and C. Gordon. New York: Wiley.

Trilling, Lionel. 1972. Sincerity and Authenticity. Cambridge, MA: Harvard University Press.

Turner, Ralph. 1976. “The Real Self: From Institution to Impulse.” American Journal of Sociology 81:989-1016.

Turner, Ralph and Charles Gordon. 1981. "The Boundaries of the Self: The Relationship of Authenticity in the Self-Conception." Pp. 39-57 in Self-Concept: Advances in Theory and Research edited by M. D. Lynch, A. A. Norem-Hebeisen, and K. J. Gergen. Cambridge, MA: Ballinger.

Turner, Ralph and Jerald Schutte. 1981. "The True Self Method for Studying the Self-Conception." Symbolic Interaction 4:1-20.

Vannini, Phillip and Dennis Waskul. 2006. "Symbolic Interaction as Music: The Esthetic Constitution of Meaning, Self, and Society." Symbolic Interaction 29:5-18.

Weinstein, Eugene and Paul Deutschberger. 1963. "Some Dimensions of Altercasting." Sociometrv 26:454-66.

White, Geoffrey and Flannery Hauck. 2000. Campus Inc.: Corporate Power in the Ivory Tower. Amherst, NY: Prometheus Books. 
